\title{
Realization and control of the Lupo EL electric vehicle
}

\author{
P.F. van Oorschot ${ }^{1}$, I.J.M. Besselink ${ }^{1}$, E. Meinders ${ }^{1}$, and H. Nijmeijer ${ }^{1}$ \\ ${ }^{I}$ Department of Mechanical Engineering, Eindhoven University of Technology, \\ P.O. Box 513, 5600 MB Eindhoven, The Netherlands \\ E-mail:p.f.v.oorschot@tue.nl
}

\begin{abstract}
During fall 2009, the Eindhoven University of Technology started the development of the Lupo EL (Electric Lightweight) research vehicle. The vehicle is fully operational now, allowed to drive on the public road and used in several research projects. This paper will focus more in-depth on the vehicle development and the research performed. The following subjects will be addressed: vehicle realization, specification and performance, data acquisition systems and control systems.
\end{abstract}

Keywords: EV (electric vehicle), data acquisition, instrumentation, regenerative braking, vehicle performance

\section{Introduction}

In recent years battery electric vehicles are receiving a lot of attention and are seen as a suitable path to reduce the dependency on oil and to allow driving with zero local emissions in city centers. Due to the limited energy density in a battery when compared to fossil fuels, it is difficult to achieve a driving range which is acceptable for the "normal user". Optimal usage of the energy stored in the batteries is a must to achieve a reasonable range.

To get a better insight in these and other aspects of electric vehicles, the Dynamics and Control group of the Eindhoven University of Technology has developed the Lupo EL electric vehicle as a research platform for electric mobility. The vehicle is designed on the basis of a VW Lupo 3L, which is thoroughly optimized to have a low weight, e.g. by having various aluminium and magnesium parts, thinner glass, etc. The resulting battery electric Lupo EL achieves a very interesting combination of interior space (4 seats), weight $(1060 \mathrm{~kg})$ and battery capacity $(27 \mathrm{kWh})$. Despite the presence of a large battery, the interior and cargo space dimensions remain unchanged. The battery chemistry used is lithium iron phosphate
$(\mathrm{LiFePO})_{4}$, which has a comparatively low cost of less than 300 euro/kWh, is considered safe and has a long cycle life. The vehicle is named Lupo EL, where the EL is the abbreviation of "Electric Lightweight". As the vehicle is designed as a research vehicle it is equipped with a large number of sensors and very flexible, programmable control systems. The most important design goals, choices and ideas have been presented during EVS25 [1].

Over the past year the realization of the Lupo EL research vehicle has been completed. The vehicle is currently functioning reliably and is homologated by the Dutch roadworthiness authorities [2].

This paper is organized as follows. Section 2 will give an overview of the vehicle realization and design choices. Attention is given to component performance and battery safety.

Section 3 investigates the vehicle performance and compares the results to the initial design goals. Special attention is given to auxiliary energy consumption.

Section 4 focuses on the vehicle control, software development and performance of the integrated traction-, cruise- and regenerative braking control. 


\section{Realization of the Lupo EL}

The Lupo EL is developed with two main goals in mind. On one hand a versatile electric research vehicle is desired with a multitude of measurement and control options. On the other hand the vehicle serves as a showcase of an affordable, practical electric vehicle which combines a good range, low weight and high efficiency. The latter function convinced us not to sacrifice any interior space; all components are mounted outside the interior space. The battery is split into three packs, two of them are mounted beneath the rear seat and under the trunk. The third battery pack as well as all other components are mounted in the engine bay. This packaging made it possible to maintain 4 seats and untouched interior space. To give an indication of the component packaging, Figure 1 and Figure 2 show the finished front and rear compartments with the battery covers removed.

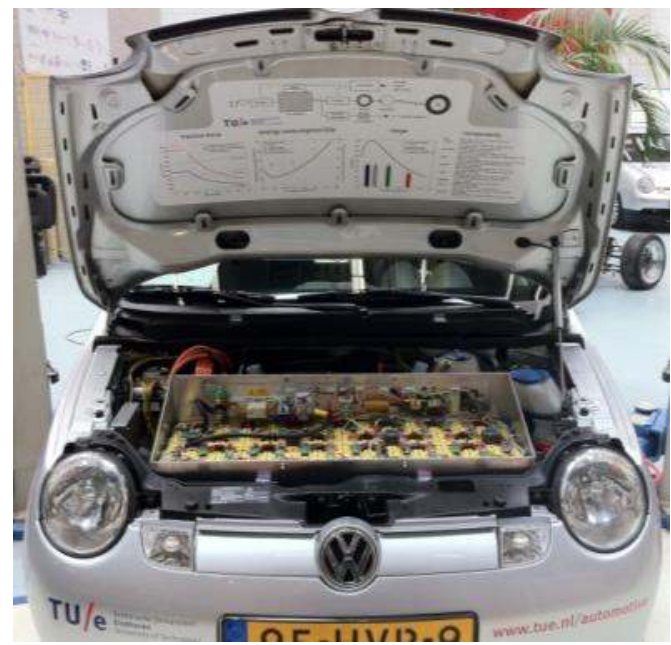

Figure 1: Front compartment with battery pack.

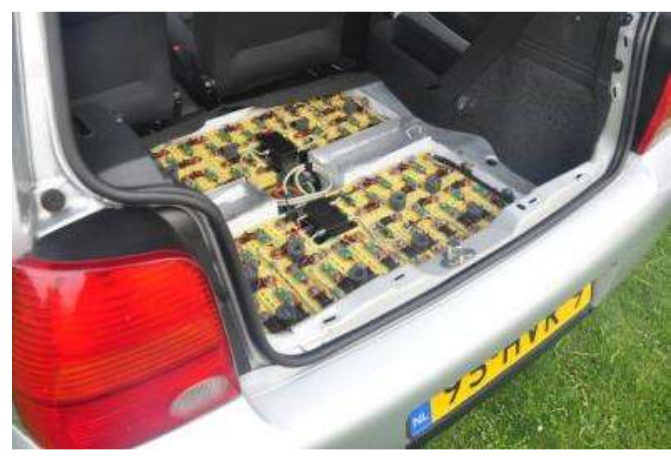

Figure 2: Rear compartment with battery packs.

Table 1 lists the driveline and other major components mounted in the Lupo EL. A more detailed description of the components and the corresponding considerations are published [1].

\begin{tabular}{|c|c|}
\hline HV batteries & $\begin{array}{l}\text { Thunder Sky/Sinopoly/Winston } \\
\text { TS-LFP90AHA, capacity } 90 \mathrm{Ah} \text {, } \\
3.3 \mathrm{~V} \text {, cycle life > } 2000 @ 80 \% \\
\text { DOD, chemistry: } \mathrm{LiFePO}_{4}, \\
91 \text { cells in series, } 273 \mathrm{~kg}, 27 \mathrm{kWh}\end{array}$ \\
\hline BMS & $\begin{array}{l}\text { Elithion Lithiumate, measurement } \\
\text { of cell voltage, temperature } \\
\text { and internal resistance, passive } \\
\text { balancing, max. balancing current } \\
200 \mathrm{~mA} \text {, CAN }\end{array}$ \\
\hline Inverter & $\begin{array}{l}\text { MES-DEA TIM } 600 \mathrm{~W} \text {, max. current } \\
236 \mathrm{~A} \text { (nominal), } 400 \mathrm{~A} \text { (peak), } \\
80 \text { - } 400 \mathrm{~V} \text { DC in, switching } \\
\text { frequency } 3-9 \mathrm{kHz} \text {, water cooled, } \\
\text { CAN }\end{array}$ \\
\hline Motor & $\begin{array}{l}\text { MES-DEA A200-200, } 24 \mathrm{~kW} / 80 \mathrm{Nm} \\
\text { (nominal), } 50 \mathrm{~kW} / 270 \mathrm{Nm} \text { (peak), } \\
\text { AC induction, } 10500 \mathrm{rpm} \text { max., } \\
\text { water cooled }\end{array}$ \\
\hline Reduction & $\begin{array}{l}\text { Carraro } 150009 \text {, single gear fixed } \\
\text { reduction, ratio } 8.654: 1\end{array}$ \\
\hline DC-DC converter & $\begin{array}{l}\text { MES-DEA 400-1000 } 150-400 \mathrm{~V} \\
\text { DC in, } 13.3-14.4 \mathrm{~V} \text { DC out, max. } \\
\text { power } 1000 \mathrm{~W} \text {, max. current } 70 \mathrm{~A} \text {, } \\
\text { air cooled }\end{array}$ \\
\hline PLC & $\begin{array}{l}\text { IFM CR0232, 32-bit CPU Infineon } \\
\text { TriCore } 1796,80 \text { IO ports, 4x CAN }\end{array}$ \\
\hline Charger & $\begin{array}{l}\text { Brusa NLG } 513 \mathrm{WC} \text {, charging } \\
\text { power } 3.3 \mathrm{~kW} \text {, } \\
260-520 \mathrm{~V} \mathrm{DC} \text { out, } \\
\text { programmable, water cooled, CAN }\end{array}$ \\
\hline Charging plug & $\begin{array}{l}\text { Mennekes 31013, } \\
\text { VDE-AR-E 2623-2-2 }\end{array}$ \\
\hline
\end{tabular}

Table 1: Component specifications.

\subsection{System layout and data acquisition}

In the design and realization of the vehicle, special attention is given to the data acquisition features. Figure 3 shows the layout of the power train, including all components connected to the high voltage battery system. The circled U, I or T symbols depict measurement points of respectively voltage, current and torque. Besides these measurements, also the energy consumption of the majority of the low voltage $12 \mathrm{~V}$ system components are measured, giving the possibility to make a detailed energy consumption analysis of the vehicle. Besides the energy consumption measurements, the vehicle is able to monitor a vast number of sensors considering the batteries, drivetrain components and vehicle dynamics. Measured parameters include vehicle accelerations, yaw rate, steering angle and much more. Additionally the existing VW systems, including ABS, airbags and dashboard are reverse engineered and fully functional in the electric vehicle. This enables monitoring the parameters measured by these systems, such as wheel speeds, active ABS systems or an airbag event. 


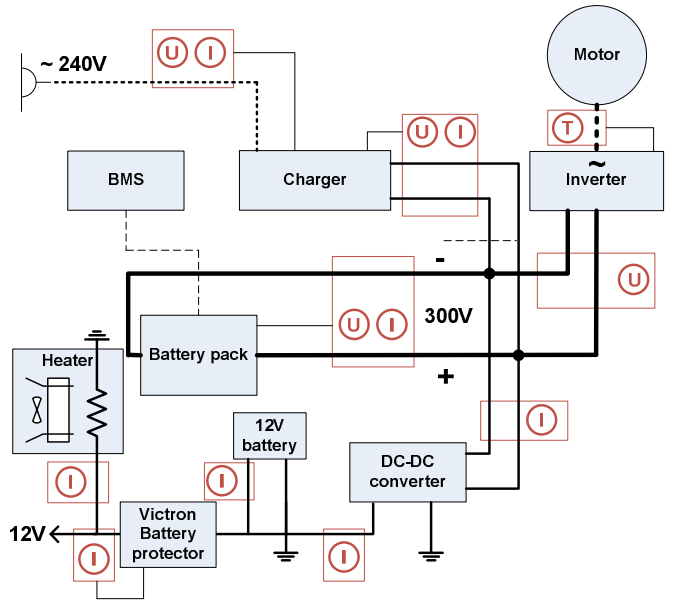

Figure 3: System layout and measurement points.

\subsection{User interface}

The original VW dashboard is used as the main interface to the driver and adapted to display the most important functions and warnings. The VW dashboard is controlled by CAN bus. All the necessary CAN addresses are obtained, making a full adaptation of the original VW dashboard possible. The modified dashboard displays the traction and regenerative power on the modified tachometer. Battery state of charge is displayed on the modified fuel gauge. The current drive modus as well as possible errors are made visible using the integrated warning lights. Figure 4 gives an impression of the adapted dashboard dial.

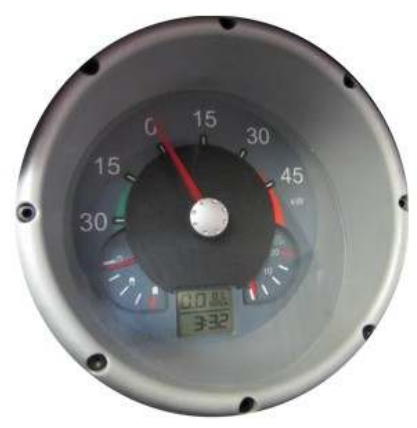

Figure 4: Adapted dashboard dial.

Besides the adapted original dashboard, a TPC66T/68T touch screen running on Windows CE is integrated in the centre console, which is capable of displaying various parameters during operation. Information related to the following topics is available: charger, $12 \mathrm{~V}$ systems, motor, battery packs, BMS, fault codes and miscellaneous other vehicle functions. The touch screen can also be used to set for example the desired charging current.

\subsection{Inverter}

The MESDEA motor inverter combination performs well in terms of power output. The motor is specified at $48 \mathrm{~kW}$ maximum power. In practice up to $70 \mathrm{~kW}$ electrical power input during traction and up to $60 \mathrm{~kW}$ electrical power output during regenerative braking have been tested for periods of more than $10 \mathrm{~s}$. The high amount of regenerated power enables regenerative braking up to high deceleration values. On the other hand external control of the inverter is difficult considering the relatively slow response to throttle or CAN bus requests. The CAN bus operates at $10 \mathrm{~Hz}$ and response delays of up to $200 \mathrm{~ms}$ are common. Furthermore very little decoupling and filtering is integrated in the inverter power stage. During initial operation, voltage transients of up to $100 \mathrm{~V}$ at the switching frequency of the inverter have been measured over the HV lines. To limit the transmission of switching harmonics onto the $\mathrm{HV}$ power lines, a low-pass LC filter is mounted between the batteries and the inverter. The LC filter consists of $8800 \mu \mathrm{F}$ capacity and a combined inductance of $160 \mu \mathrm{H}$, establishing a filter cutoff frequency of $134 \mathrm{~Hz}$. Figure 5 displays the filter design.

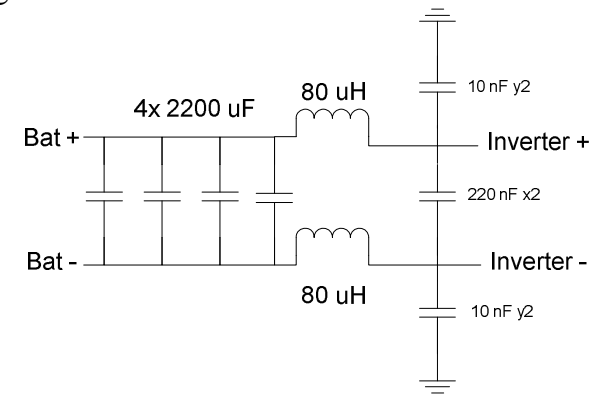

Figure 5: Low pass filter layout.

\subsection{Battery safety and performance}

The chosen battery cells, the LFP90AHA Thunder Sky (currently manufactured under the names Winston and Sinopoly) are specified for a nominal continuous load up to $3 \mathrm{C}$ or $270 \mathrm{~A}$. In the Lupo EL the maximum current is limited by the inverter settings at $200 \mathrm{~A}$ during acceleration, the nominal current at a constant speed of $100 \mathrm{~km} / \mathrm{h}$ is approximately $50 \mathrm{~A}$. The load on the battery is therefore relatively low and does not pose any problems in terms of battery power. To quantify the performance and efficiency of the cells, a single LFP90AHA cell has been tested at constant currents of 50 up to $500 \mathrm{~A}$.

To determine the safety of a single cell under extreme conditions, a fully charged cell is 
connected in short-circuit while current, voltage and temperature are monitored.

\subsubsection{Battery efficiency}

Figure 6 shows a schematic of the measurement circuit used during the cell tests; $r$ denotes the cell internal resistance, $R$ the external resistance (including shunt and connection resistances), $E$ the cell emf (electromotive force) voltage. The voltage is measured over the cell terminals, the terminal voltage. The current is measured using an in-circuit shunt, this shunt has a $60 \mathrm{mV}$ voltage drop at $2500 \mathrm{~A}$. The temperature is measured using a thermocouple mounted at the centre of the battery cell.

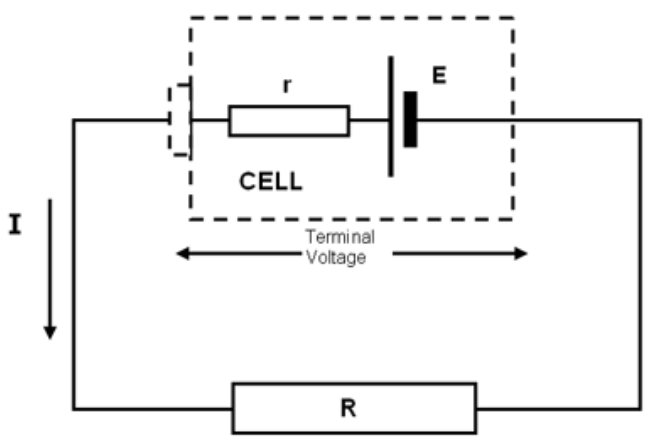

Figure 6: Battery cell measurement setup.

As the terminal voltage and system current are measured, the internal resistance $r$ and the external resistance $R$ values can be determined and the internally dissipated power $P_{i n}$ and externally dissipated power $P_{e x}$ can be calculated.

$P_{\text {in }}=I^{2} * r$

$P_{e x}=I^{2} * R$

This data makes it possible to determine the cell efficiency $\eta_{\text {cell }}$.

$\eta_{\text {cell }}=P_{e x} /\left(P_{i n}+P_{e x}\right)$

The cell is tested at the following nominal currents: 50/100/200/300/400/500 A. All tests have been repeated 3 times with a duration of 30 $\mathrm{s}$ and intervals of $60 \mathrm{~s}$ between the tests. The results are averaged over the 3 subsequent tests. The efficiency of the cell at the different loads is calculated at the start and end of the tests. Figure 7 shows the cell efficiency versus the load currents.

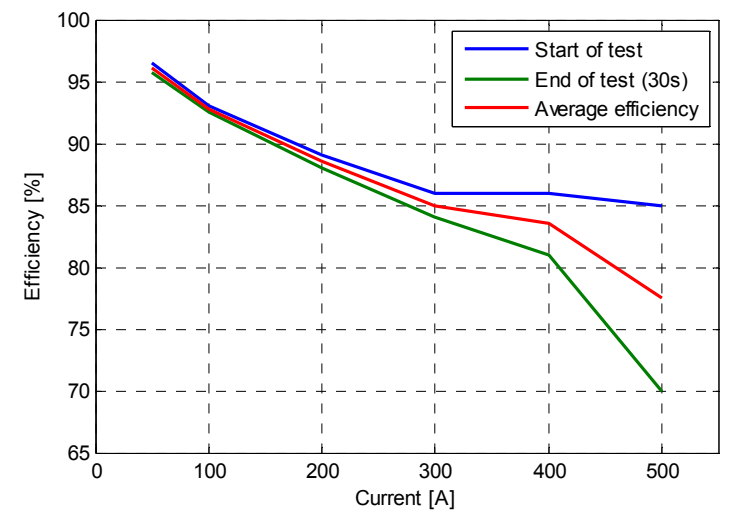

Figure 7: Battery efficiency depending on load current.

The discharge measurements show that the efficiency of the cells at a nominal vehicle load of $50 \mathrm{~A}$ is approximately $95 \%$, at the peak load of $200 \mathrm{~A}$ it drops to $88 \%$. For currents above $300 \mathrm{~A}$ the discharge efficiency drops significantly during the $30 \mathrm{~s}$ test.

\subsubsection{Short circuit safety test}

One of the reasons to select the $\mathrm{LiFePO}_{4}$ chemistry is safety. The strong covalent bonding between the oxygen and phosphate makes this chemistry more stable than for example lithium cobalt oxide [3]. To assess the safety of the cells, a short circuit test is performed to determine the behavior under extreme circumstances.
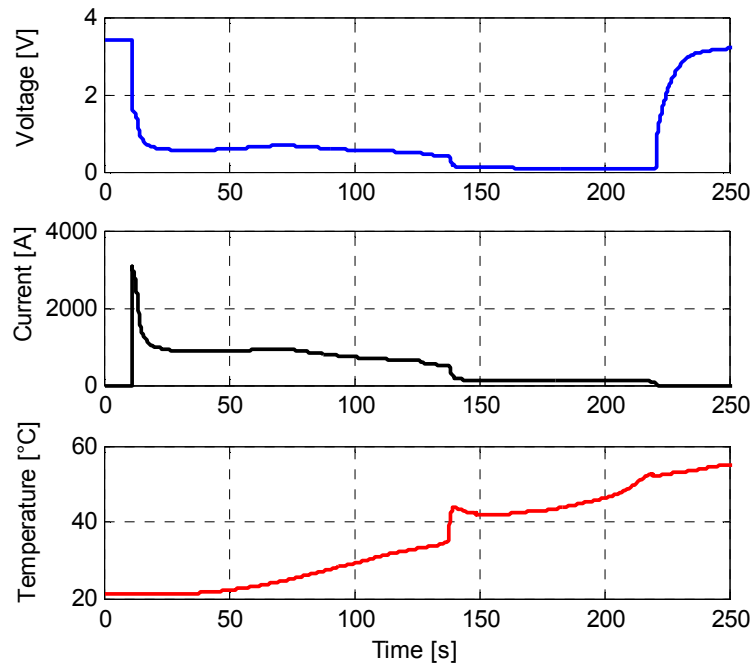

Figure 8: Measured parameters during short-circuit.

For this test a single, fully charged, cell is connected in short circuit. The peak current observed during the short circuit test is $3050 \mathrm{~A}$, the next seconds the current declines at a rapid pace to a value around $900 \mathrm{~A}$ and stays relatively constant for the following minute. Figure 8 shows the current, voltage and temperature during the test. 
After approximately $100 \mathrm{~s}$ in short-circuit condition, the cell starts to swell somewhat. After $118 \mathrm{~s}$ the cell starts venting, $8 \mathrm{~s}$ later the housing cracks at the top of the cell and electrolyte is released from the cell. At this point, the current steeply declines from 500 A to $140 \mathrm{~A}$.

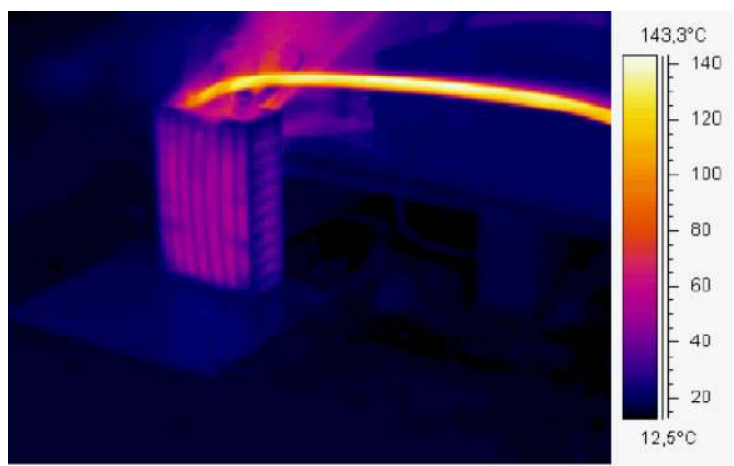

Figure 9: Thermal camera picture of cell venting.

During the short circuit test, the cell casing heats up relatively slow. The cell casing temperature is approximately $45^{\circ} \mathrm{C}$ at the moment the electrolyte vents. Figure 9 displays a thermal image during the cell venting. During the test no fire or explosion occurs. The electrolyte itself however is flammable. Under normal circumstances the fuse and safety systems will break the short circuit within seconds in case of a short-circuit event.

\subsection{Efficient xenon lighting}

Lighting constitutes a significant part of the auxiliary power consumption in an electric vehicle. In cooperation with Philips Automotive Lighting [4], a new, low power xenon bulb is tested in the Lupo EL. While in general xenon lights have about the same energy consumption as halogen lights, but about twice the light production in lumen, the tested $25 \mathrm{~W}$ Philips D5S xenon lights provide the same amount of lumen as original halogen lights, but with half the power consumption. In Figure 10 the energy consumption of a pair of headlights is compared. The comparison includes original halogen $(60 / 55 \mathrm{~W})$, Philips ecovision efficient halogen $(60 / 55 \mathrm{~W})$ and the xenon D5S $(25 \mathrm{~W})$ lights, all tests have been performed at $13 \mathrm{~V}$. While the xenon bulbs have a slightly higher consumption of $30 \mathrm{~W}$ per bulb instead of the $25 \mathrm{~W}$ specificated. The results show a clear benefit of the low power xenon lighting.

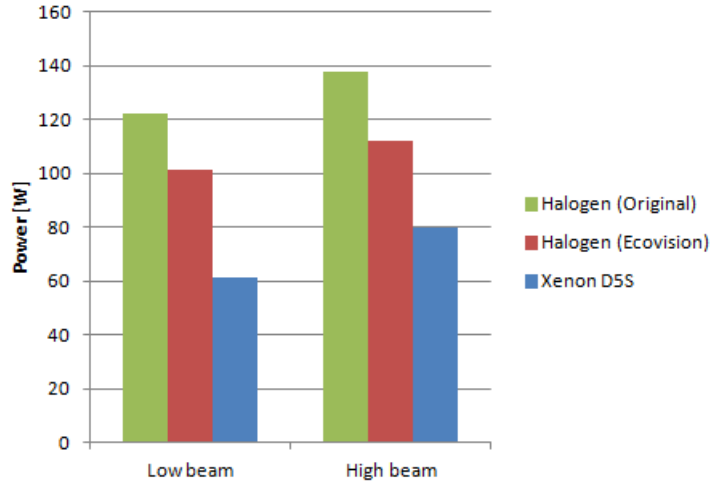

Figure 10: Lighting energy consumption.

The energy savings are equal to $40 \mathrm{~W}$ or $39 \%$ compared to the efficient halogen bulbs and $60 \mathrm{~W}$ or $50 \%$ compared to the conventional halogen lighting. An interesting observation is that the increased power consumption for high beam lighting originates solely from the actuation of a shutter solenoid.

\subsection{Weight analysis}

After the completion of the vehicle, a full weight analysis of the vehicle and component weights is performed and the initial weight analysis is updated. Table 2 shows the final weight breakdown analysis of the completed Lupo EL compared to the original Lupo $3 \mathrm{~L}$ vehicle.

\begin{tabular}{l|r|r|l} 
& Lupo 3L & Lupo EL & \\
\hline vehicle mass (no power train) & 599 & 595 & $\mathrm{~kg}$ \\
& & & \\
motor + gear box + drive shafts & 180 & 85 & $\mathrm{~kg}$ \\
cooling (radiator, hoses, etc.) & 10 & 7 & $\mathrm{~kg}$ \\
exhaust & 15 & & $\mathrm{~kg}$ \\
power electronics & & 25 & $\mathrm{~kg}$ \\
fuel tank + cooler + filter & 9 & & $\mathrm{~kg}$ \\
diesel (7 liters) & 6 & & $\mathrm{~kg}$ \\
battery pack front (8.3 kWh) & & 84 & $\mathrm{~kg}$ \\
battery pack center (7.7 kWh) & & 78 & $\mathrm{~kg}$ \\
battery pack rear (11.0 kWh) & 20 & 111 & $\mathrm{~kg}$ \\
battery 12 V & 8 & 69 & $\mathrm{~kg}$ \\
miscellaneous (wiring, etc.) & 248 & 465 & $\mathrm{~kg}$ \\
\hline complete power train & 847 & 1060 & $\mathrm{~kg}$ \\
total vehicle mass & $64 / 36$ & $58 / 42$ & $\%$ \\
distribution (front/rear) & &
\end{tabular}

Table 2: Vehicle weight breakdown.

The final curb weight equals $1060 \mathrm{~kg}$, slightly over the design goal of $1000 \mathrm{~kg}$, but nonetheless a very low weight for an BEV with a battery capacity of $27 \mathrm{kWh}$. For example a Mitsubishi iMiEV weights $1080 \mathrm{~kg}$, but has an available battery capacity of only $16 \mathrm{kWh}$. A Nissan Leaf weights $1540 \mathrm{~kg}$, considerably more than the Lupo EL, but has a battery capacity of $24 \mathrm{kWh}$. 


\section{Performance review}

The initial design goals for the Lupo EL where specified as follows [1]:

- top speed $>120 \mathrm{~km} / \mathrm{h}$

- acceleration time $0-100 \mathrm{~km} / \mathrm{h}<15 \mathrm{~s}$

- charging time of 8 hours or less on a standard power socket $(230 \mathrm{~V} / 16 \mathrm{~A})$

- $\quad$ slope climbing ability $>30 \%$ grade

- range of $200 \mathrm{~km}$

- curb weight below $1000 \mathrm{~kg}$

The design goals have been achieved within a reasonable margin, the individual design goals will be briefly discussed. Extra attention is given to the vehicle and component energy consumption.

Top speed design goal is achieved; the top speed is electronically limited at $130 \mathrm{~km} / \mathrm{h}$ to limit the maximum engine speed to $10500 \mathrm{rpm}$.

Acceleration The Lupo EL accelerates 0-100 $\mathrm{km} / \mathrm{h}$ in $12 \mathrm{~s}$, which is well within the design goal of $15 \mathrm{~s}$. Figure 11 shows the measured acceleration performance.

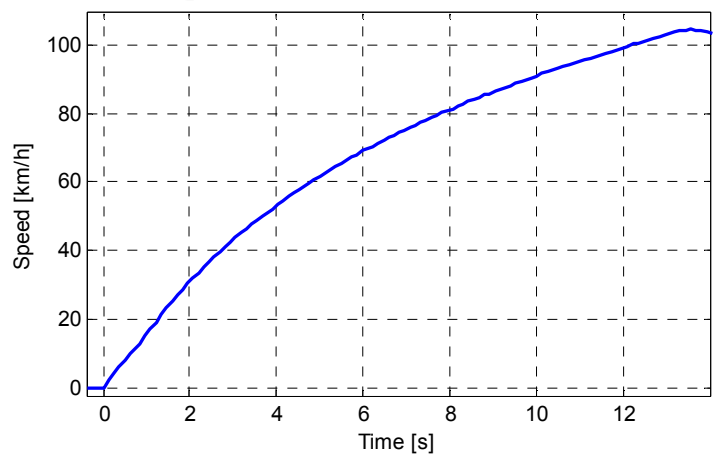

Figure 11: Measured acceleration $0-100 \mathrm{~km} / \mathrm{h}$.

Charging time design goal is achieved; the charger can output $3 \mathrm{~kW}$ DC continuously. This enables charging of $24 \mathrm{kWh}$ in 8 hours, which is more than the nominal $80 \%$ of the maximum battery capacity $(21.6 \mathrm{~kW})$. Because of the relative slow charging, $3 \mathrm{~kW}$ charging power is possible up to $95 \%$ capacity.

Slope climbing goal is achieved; the Lupo EL is calculated to be able to climb hills up to $40 \%$ considering the available motor torque. The hill climbing performance at $30 \%$, including startstop maneuver, has been tested at the RDW proving grounds in Lelystad, the Netherlands, see Figure 12.

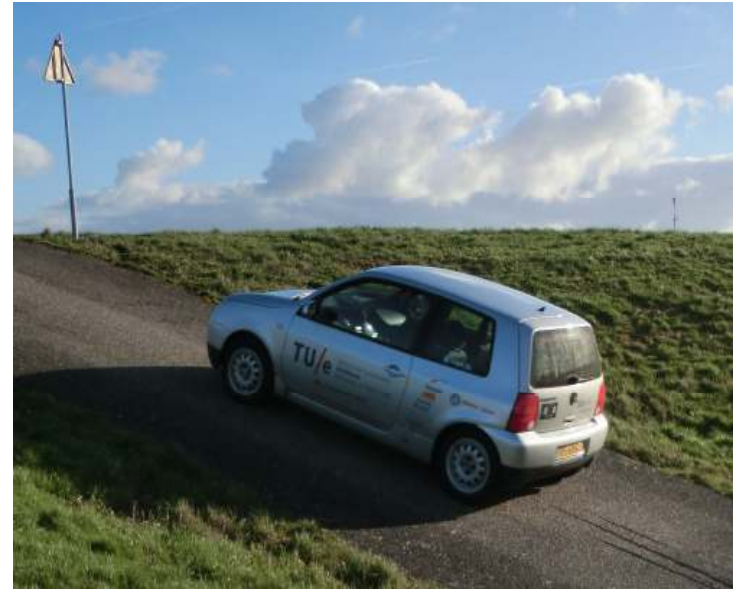

Figure 12: Test on a $30 \%$ slope.

\subsection{Energy consumption and range}

The vehicle energy consumption is evaluated under several conditions. Tests have been performed at $20{ }^{\circ} \mathrm{C}$ during summer, currently tests are performed during winter conditions at $5{ }^{\circ} \mathrm{C}$. Preliminairy test results are displayed in Figure 13. As expected, cold temperatures have a negative impact on the vehicle DC energy consumption and range. A study on the range and energy consumption of a converted VW Golf Variant electric vehicle, spanning more than $20000 \mathrm{~km}$, shows a significant negative influence of the ambient temperature on specific energy consumption [5]. Not considering interior heating requirements, the specific energy consumption increases at lower temperatures due to several reasons. For example the air density and therefore aerodynamic drag increases $5.7 \%$ at $5{ }^{\circ} \mathrm{C}$ compared to $20^{\circ} \mathrm{C}$. Another factor is the tyre rolling resistance which tends to increase at lower temperatures [6].

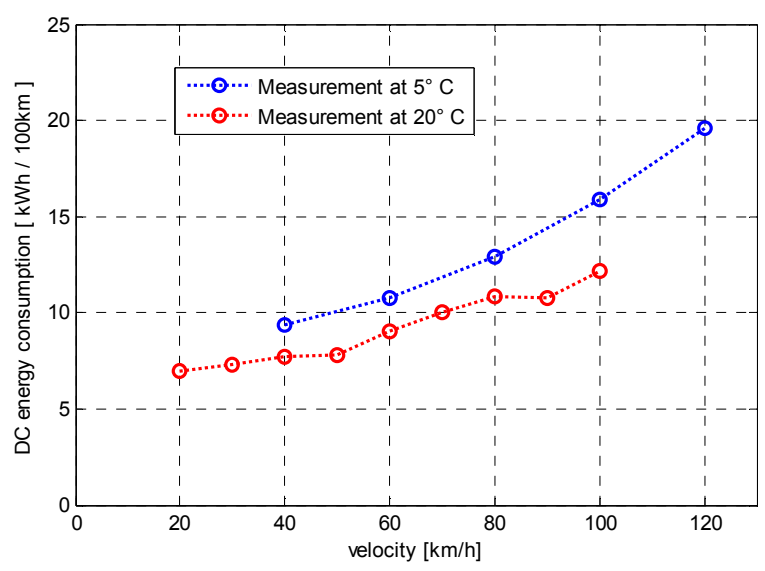

Figure 13: Preliminary results at constant velocity. 
The experiments during winter time have been performed on the RDW proving grounds, using an oval test track. Therefore these measurements are of a higher quality than the summer measurements which have been performed on the public road. Several additional experiments, including drive cycles, are planned the coming periods to obtain a better insight in energy consumption under different circumstances.

During the experiments performed at $5^{\circ} \mathrm{C}$, the maximum range at a constant speed of $100 \mathrm{~km} / \mathrm{h}$ has been determined by driving the vehicle at the oval track until the battery was depleted. A total distance of $144 \mathrm{~km}$ at a constant velocity of $100 \mathrm{~km} / \mathrm{h}$ has been travelled on a full charge at $5{ }^{\circ} \mathrm{C}$. The Lupo EL has participated in several EV rallies, at which energy consumption has been measured. These include the 2011 Future car challenge, driven from Brighton to London spanning a distance of 95.4 kilometer. The measured DC energy consumption during this trip was $10.68 \mathrm{kWh}$, resulting in a specific energy consumption of $12.26 \mathrm{kWh} / 100 \mathrm{~km}$. Another event the Lupo EL participated in was the 2010 Michelin Challenge Bibendum. During this challenge a route of $125 \mathrm{~km}$ was driven. At the Challenge Bibendum, the Lupo EL was the overal winner in its class.

\subsection{Component energy consumption}

The power consumption of the majority of components in the low voltage (LV) system are logged. This enables a more detailed study of individual component contribution to the auxiliary energy consumption. Figure 14 displays the LV auxiliary power consumption of the components, with and without low beam lighting enabled. When no low beam is enabled, LED daylight running lights are enabled.

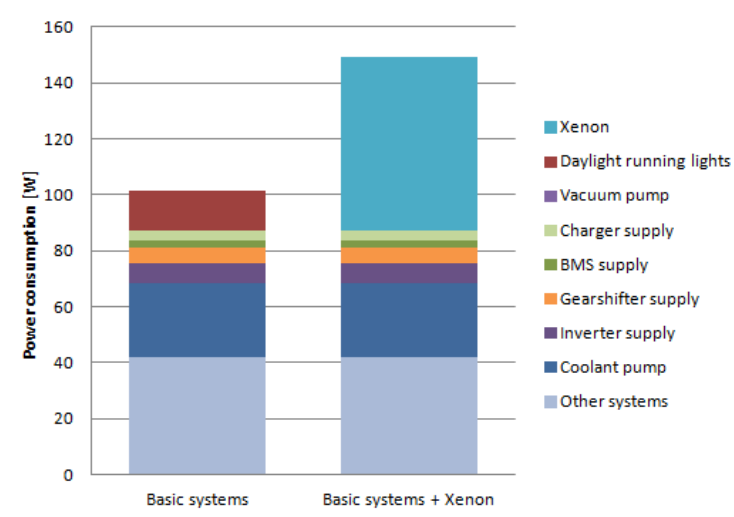

Figure 14: Auxiliary energy consumption breakdown.
The results show that the lighting and the coolant pump are the most consuming individual components. The power consumption of the other systems consist of existing VW systems, such as ABS, dashboard lighting, etc. LV power consumption with low beam turned off is equal to $100 \mathrm{~W}$, with low beam xenon turned on $150 \mathrm{~W}$. At these power levels, the DC-DC converter operates at an efficiency of $72 \%$, which leaves room for improvement. This results in a HV auxiliary power consumption requirement at the batteries of $138 \mathrm{~W}$ without low beam and $207 \mathrm{~W}$ with low beam.

\section{Software and control}

An IFM CR0232 PLC (Programmable Logic Controller) serves as the main vehicle controller. It monitors the data from all sensors and components and serves as the master controller for all vehicle systems. The controller utilizes 80 IO ports and 4 CAN busses. Where possible communication is performed via CAN bus to reduce cabling and maximize flexibility. Multiple CAN busses are used to increase system redundancy.

\subsection{Software structure}

The PLC software consists of a main program which sequentially calls sub-functions. The main program cycle runs continuously.

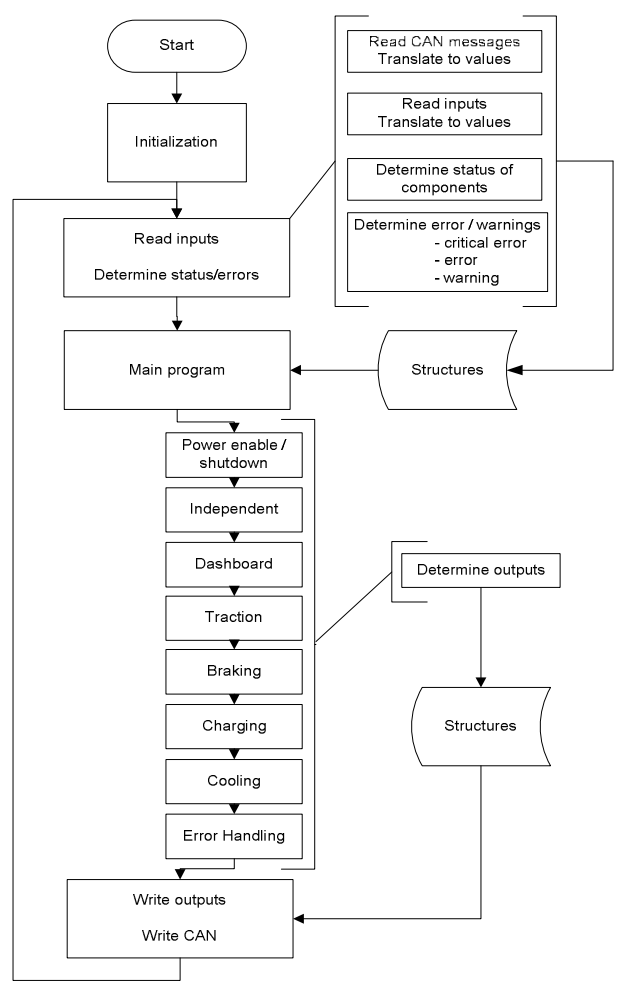

Figure 15: PLC program cycle structure. 
The current cycle time is approximately $7 \mathrm{~ms}$. The PLC is programmed according to the IEC 61131-3 standard. Most sub-programs are programmed using function block diagrams, as this improves the visual readability of the code and program structure.

Figure 15 shows a schematic of a main program cycle. At first all inputs and CAN bus messages are read, converted to physical values, analyzed for discrepancies or possible errors or faults and are stored. All programs and functions are ordered by priority and the output values of the functions and programs are temporarily stored. By placing the highest priority functions at the end of the cycle, they are able to override earlier decisions. After the highest priority function, error handling, has run, the output IO and CAN messages are send.

\subsection{Cruise control}

A cruise control has been developed for the Lupo EL. The original gear-shifter sport position is used to enable cruise control. The gear lever sport plus and minus position, normally used for manual gear selection, can now be used to increase or decrease the cruise control speed.

Multiple safety mechanisms are included to switch off the cruise control in case the brake pedal is pressed. Brake actuation is measured by dual hard-wired brake switches and a brake pressure sensor.
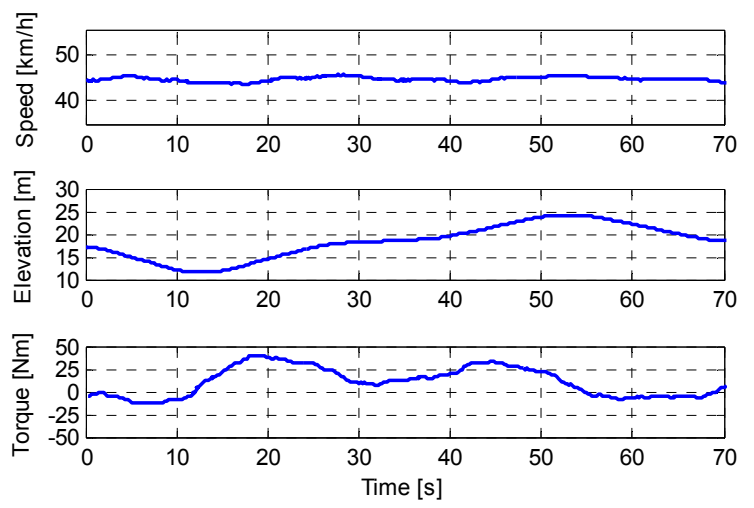

Figure 16: Cruise control performance on slopes.

A PI controller is programmed in the PLC to control the inverter throttle request, it uses the desired speed as a setpoint and the average rearwheel speed as feedback. An example of a cruise control performance test is driving through a tunnel and on a flyover in Eindhoven at a speed of $45 \mathrm{~km} / \mathrm{h}$ with hill grades up to $5 \%$. During this test the vehicle speed deviates less than $\pm 3 \%$ from the desired speed. Figure 16 displays the speed, road elevation and motor torque over time during this experiment. Elevation is measured by a high precision OXTS GPS sensor system.

\subsection{Traction control}

A traction control algorithm is developed to optimize acceleration and vehicle control under slippery conditions. The algorithm is programmed in the PLC and can limit the throttle request for the inverter, by multiplying the original throttle request with a scaling factor which can have a value between 0 and 1 . The throttle scaling is determined by analyzing the relative slip of the driven front wheel speed versus the non-driven rear wheel speed. The relative slip $\kappa$ is determined as.

$\kappa=\left(\omega_{\text {front }}-\omega_{\text {rear }}\right) / \omega_{\text {front }}$

When the relative slip rises above $5 \%$, the traction control scaling linearly decreases, down to a minimum value of 0.1 at a relative slip of $15 \%$ or more. Below a speed of $10 \mathrm{~km} / \mathrm{h}$ an absolute slip of $5 \mathrm{~km} / \mathrm{h}$ is allowed for better traction when driving off on very slippery surfaces.

Unfortunately the inverter has a very limited bandwidth and a response delay of up to $200 \mathrm{~ms}$. This limits the ability to develop a fast controller. Still a good overall result can be obtained by limiting the rate at which the traction control scaling and thus traction power is increased. A rate of 0.2 per second works satisfactory.

The resulting traction control is tested on, e.g. snow and performs well. Figure 17 displays the front and rear wheel speeds during this run with traction control enabled.

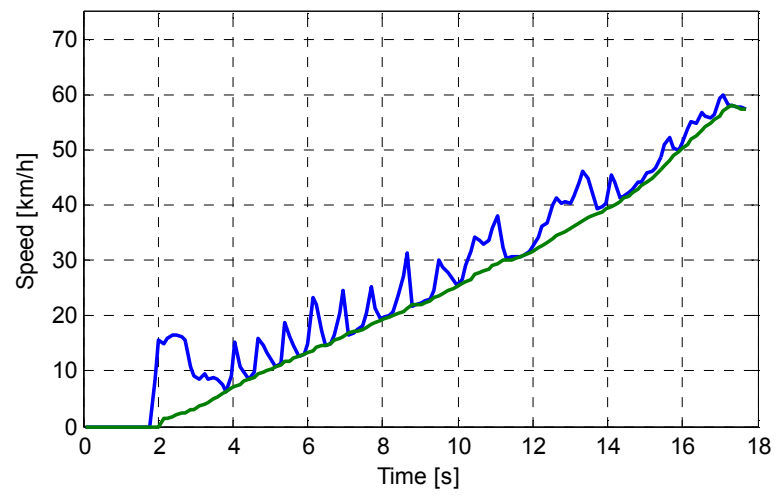

Figure 17: Traction control performance on snow. 


\subsection{Regenerative braking control}

Regenerative braking of electric vehicles offers several advantages but poses challenges as well. By maximizing the use of regenerative braking, the overall energy consumption can be lowered resulting in an increased vehicle range. Due to a good weight distribution and a comparatively large battery, a high amount of regenerative braking power is available in the Lupo EL. Currently up to $50 \mathrm{~kW}$ regenerative braking is applied at the front wheels. Unlike many other battery electric vehicles, this is equal to the maximum traction power and the usage of the friction brakes can be limited. Heavy regenerative braking however can impede the vehicle stability, for example on slippery roads or during cornering. Also a consistent brake pedal feel is important, as the brakes have to be relied upon by the driver in critical driving situations. So the challenge is to maintain a safe and reliable operation of the braking system, while maximizing energy recuperation.

The original braking system is left untouched, including ABS functionality. This ensures a reliable hydraulic braking system which functions under all circumstances. This however implicates that some hydraulic braking will always take place whenever the brake pedal is pressed.

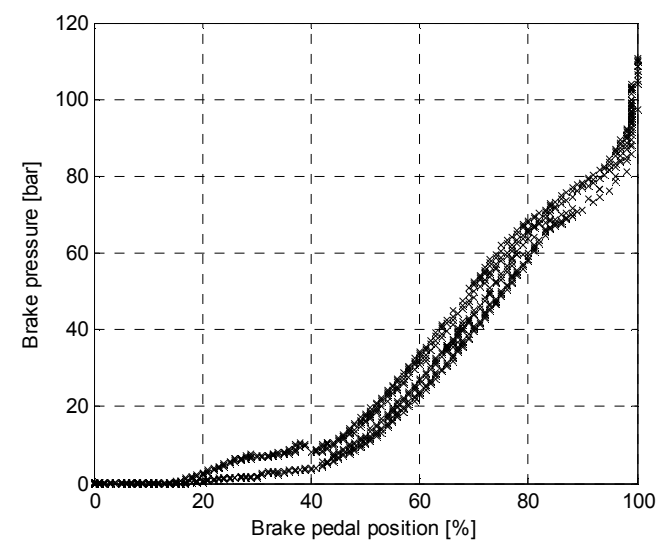

Figure 18: Brake pedal position versus pressure.

Figure 18 displays the pressure buildup in the hydraulic braking system depending on the brake pedal position. The first part of the curve shows a slow buildup of pressure relative to pedal position. This is probably caused by the required movement of the brake pads before the friction material contacts the brake discs and drums. This behavior is utilized to maximize regenerative braking, while the friction brakes are hardly braking.
For control of the regenerative braking, the throttle pedal position, brake pedal position, brake system pressure and wheel speeds can be used as inputs for the control strategy. Several brake control strategies have been developed [7] and have been tested. Figure 19 displays the currently used control strategy which is based on the measured brake pressure in the master cylinder. The use of brake pressure as the main control parameter helps to maintain a consistent pedal feel and brake blending, as braking force is coupled to the feedback force felt at the brake pedal. The regenerative braking offset at zero brake pressure, is controlled by the throttle pedal release. Currently, throttle release leads to a deceleration of $0.5 \mathrm{~m} / \mathrm{s}^{2}$.

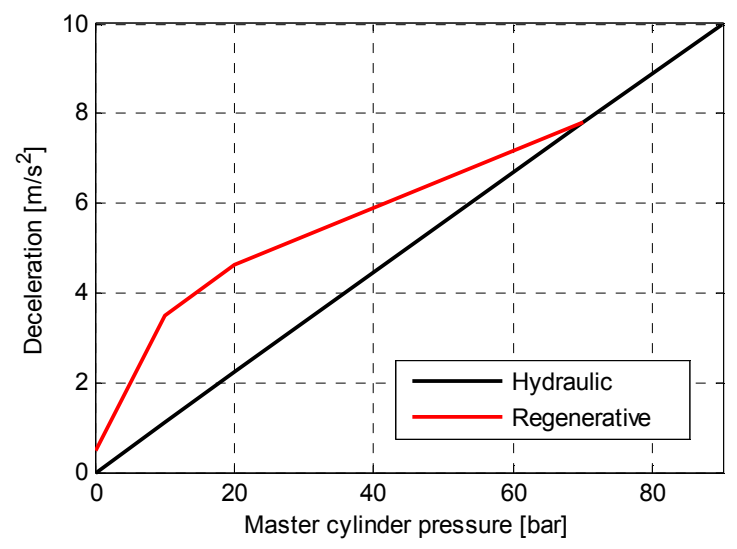

Figure 19: Additional regenerative braking algorithm.

The current algorithm uses the first $40 \%$ of brake pedal movement to increase regenerative braking torque depending on brake pressure. Maximum regenerative braking is obtained at a brake pressure of 10 bar. The additional regenerative deceleration at this point is approximately $2 \mathrm{~m} / \mathrm{s}^{2}$. During normal driving, deceleration at 1 to $3 \mathrm{~m} / \mathrm{s}^{2}$ is common. The regenerative deceleration is kept constant but can be limited by maximum power.

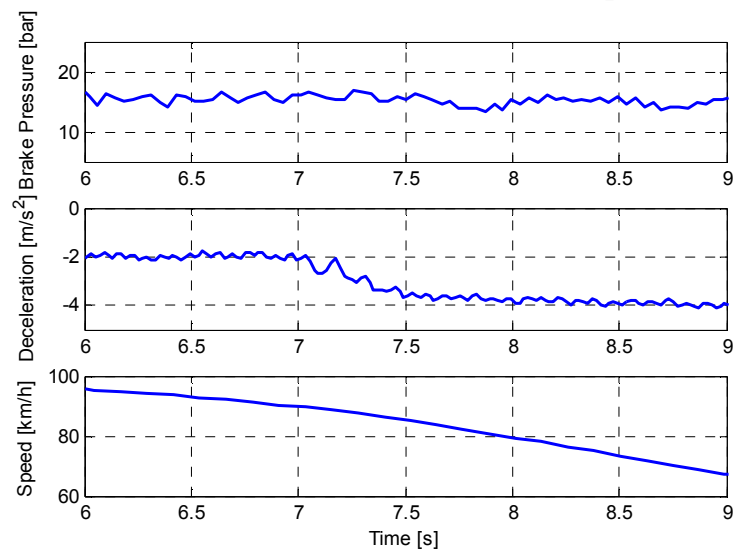

Figure 20: Regenerative braking deceleration. 
At brake pressures above 20 bar, regenerative braking is decreased linearly to zero at 70 bar. This is done to maintain a good brake balance and stability in the case of emergency stops. Also regenerative braking is completely disabled in case the ABS system becomes active.

Figure 20 displays the resulting deceleration due to regenerative braking. During this experiment, the brake pressure is kept constant at 15 bar. At the start of the experiment regenerative braking is disabled while at $7 \mathrm{~s}$ regenerative braking is enabled. As a result the vehicle deceleration doubles from $2 \mathrm{~m} / \mathrm{s}^{2}$ to $4 \mathrm{~m} / \mathrm{s}^{2}$. The resulting deceleration of $4 \mathrm{~m} / \mathrm{s}^{2}$ consists of a deceleration of approximately $0.5 \mathrm{~m} / \mathrm{s}^{2}$ by the aerodynamic drag and rolling resistance, $1.5 \mathrm{~m} / \mathrm{s}^{2}$ by the hydraulic braking system and $2 \mathrm{~m} / \mathrm{s}^{2}$ by regenerative braking.

\section{Conclusions}

The realization of the Lupo EL research vehicle is completed during the last year and the vehicle proves to be a very versatile platform for research on subjects related to electric mobility. The initial design goals have been achieved within reasonable margins. During the realization several components have been tested and in general the performance agrees to the specifications. The used $\mathrm{LiFePO}_{4}$ batteries have been tested, function at high efficiency at nominal load and prove to be relatively safe. The integration of additional regenerative braking based on the brake pressure as an input, while leaving the original brake system intact, functions well in terms of brake blending. Energy recuperation during regenerative braking could be further optimized. Future research activities include the characterization and modeling of the vehicle energy consumption under different circumstances, the development of regenerative braking stability control and investigation of energy efficient electric vehicle interior heating methods.

\section{Acknowledgments}

The authors would like to thank: Philips Automotive Lighting, Rijksdienst voor wegverkeer (RDW), TE connectivity, Michelin, Winston battery, Siba fuses, AEP, Bender, Mennekes, $\mathrm{C}, \mathrm{mm}, \mathrm{n}$ and Peter Augsten cable.

\section{References}

[1] I.J.M. Besselink, P.F. van Oorschot, E. Meinders, H. Nijmeijer, Design of an efficient, low weight battery electric vehicle based on a VW Lupo 3L, EVS 25 Shenzen, 59 November 2010

[2] Website: http://www.rdw.nl

[3] Tang, Ping and Holzwarth, N. A. W. Electronic structure of $\mathrm{FePO} 4, \mathrm{LiFePO}$, and related materials, Physical Review B 68, 2003

[4] Website: http://www.lighting.philips.com

[5] I.J.M. Besselink, J.A.J. Hereijgers, P.F. van Oorschot, H. Nijmeijer, Evaluation of 20000 $\mathrm{km}$ driven with a battery electric vehicle, EEVC Brussels, 26-28 October 2011

[6] Booklet: The tyre, rolling resistance and fuel savings, Société de Technologie Michelin, 2003

[7] K.H.R. Broeksteeg, Parallel regenerative braking control for the TU/e Lupo EL, MSc thesis, Eindhoven University of Technology, 2011

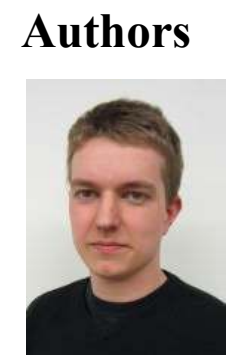

Paul van Oorschot MSc. is a research scientist at the Eindhoven University of Technology, department of Mechanical Engineering, Dynamics and Control. Current research activities include electric vehicles and battery management systems.

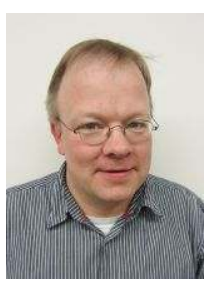

Dr. Ir. Igo Besselink is an assistant professor at the Eindhoven University of Technology, department of Mechanical Engineering, Dynamics and Control. Research activities include tyre modelling, vehicle dynamics and electric vehicles.

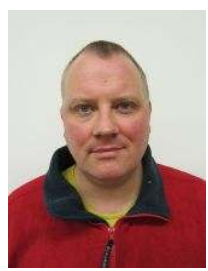

Erwin Meinders is a technical employee working on several projects in the famous automotive engineering science lab. Activities include vehicle dynamic test setups, electric vehicle research and practical exercises in the field of power trains.

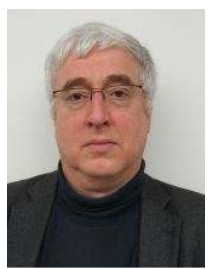

Prof. Dr. Henk Nijmeijer is a full professor at the Eindhoven University of Technology, department of Mechanical Engineering, Dynamics and Control. Current research activities include non-linear dynamics and control. 